\title{
Administration of probiotics Lactobacillus rhamnosus GG and Lactobacillus gasseri K7 during pregnancy and lactation changes mouse mesenteric lymph nodes and mammary gland microbiota
}

\author{
P. Treven, ${ }^{* 1}$ V. Mrak,† B. Bogovič Matijašić, ${ }^{*}$ S. Horvat, †‡ and I. Rogelj* \\ *University of Ljubljana, Biotechnical Faculty, Institute of Dairy Science and Probiotics, Groblje 3, SI-1230 Domžale, Slovenia \\ †University of Ljubljana, Biotechnical Faculty, Chair for Genetics, Animal Biotechnology and Immunology, Groblje 3, SI-1230 Domžale, Slovenia \\ ¥National Institute of Chemistry, Hajdrihova 19, SI-1001, Ljubljana, Slovenia
}

\begin{abstract}
The milk and mammary gland (MG) microbiome can be influenced by several factors, such as mode of delivery, breastfeeding, maternal lifestyle, health status, and diet. An increasing number of studies show a variety of positive effects of consumption of probiotics during pregnancy and breastfeeding on the mother and the newborn. The aim of this study was to investigate the effect of oral administration of probiotics Lactobacillus gasseri $\mathrm{K} 7$ (LK7) and Lactobacillus rhamnosus GG (LGG) during pregnancy and lactation on microbiota of the mouse mesenteric lymph nodes (MLN), MG, and milk. Pregnant FVB/N mice were fed skim milk or probiotics LGG or LK7 resuspended in skim milk during gestation and lactation. On d 3 and 8 postpartum, blood, feces, MLN, MG, and milk were analyzed for the presence of LGG or LK7. The effects of probiotics on MLN, MG, and milk microbiota was evaluated by real-time PCR and by $16 \mathrm{~S}$ ribosomal DNA 454-pyrosequencing. In 5 of 8 fecal samples from the LGG group and in 5 of 8 fecal samples from the LK7 group, more than $1 \times 10^{3}$ of live LGG or LK7 bacterial cells were detected, respectively, whereas no viable LGG or LK7 cells were detected in the control group. Live lactic acid bacteria but no LGG or LK7 were detected in blood, MLN, and MG. Both probiotics significantly increased the total bacterial load as assessed by copies of $16 \mathrm{~S}$ ribosomal DNA in MLN, and a similar trend was observed in MG. Metagenomic sequencing revealed that both probiotics increased the abundance of Firmicutes in MG, especially the abundance of lactic acid bacteria. The Lactobacillus genus appeared exclusively in MG from probiotic groups. Both probiotics influenced MLN microbiota by decreasing diversity (Chao1) and increasing the distribution of species (Shannon index). The LGG probiotic also affected the MG microbiota
\end{abstract}

Received June 24, 2014.

Accepted December 9, 2014.

${ }^{1}$ Corresponding author: Primoz.Treven@bf.uni-lj.si as it increased diversity and distribution of species and proportions of the genera Lactobacillus and Bifidobacterium. These results provide evidence that probiotics can modulate the bacterial composition of MLN and MG microbiota in ways that could improve the health of the MG and, ultimately, the health of the newborn. Key words: probiotics and pregnancy, mammary gland microbiota, 454-pyrosequencing, mesenteric lymph node

\section{INTRODUCTION}

In the last decades, the use of more sophisticated culture-dependent and culture-independent techniques has revealed that breast milk is a complex ecosystem containing representatives of various bacterial phyla, including Firmicutes, Bacteroidetes, Actinobacteria, and Proteobacteria (Jeurink et al., 2013; Jost et al., 2013). These bacteria may originate from the skin and newborn oral cavity, which is infected with vaginal and intestinal microbiota during childbirth. During breastfeeding and nursing, bacteria from the neonatal mouth colonize the alveoli and milk ducts (West et al., 1979; Mackie et al., 1999; Heikkilä and Saris, 2003). For some of the bacteria present in breast milk (strictly anaerobic species, lactobacilli and bifidobacteria), skin is a very unlikely source. Several findings suggest that colonization of the mammary ducts and areola by specific maternal gut bacteria during pregnancy and lactation is achieved through an endogenous route (the so-called entero-mammary pathway), involving maternal dendritic cells or macrophages (Martín et al., 2004; Perez et al., 2007). This hypothesis was supported by recent findings that a viable strain of Bifidobacterium breve was vertically transferred from mother to neonate via breastfeeding (Jost et al., 2014).

The milk microbiome can be influenced by several factors, such as mode of delivery, breastfeeding, maternal lifestyle, health status, and diet (i.e., use of antibiotics or probiotics; Cabrera-Rubio et al., 2012; Collado et al., 2012; Fernandez et al., 2013; Soto et al., 2014). An 
increasing number of studies shows a variety of positive effects of consumption of probiotics during pregnancy and breastfeeding on mother and newborn (Gueimonde et al., 2006; Huurre et al., 2008; Kopp et al., 2008; Ortiz-Andrellucchi et al., 2008; Grönlund et al., 2011; Grzeskowiak et al., 2012; Asemi et al., 2013). However, the mechanisms by which probiotics consumed during pregnancy and lactation affect the milk microbiota remain elusive. Theoretically, the milk microbiota can be affected in at least 3 different ways, which appear to be linked: (1) probiotics can affect the immune system of the mother, which indirectly affects the milk microbiota composition (Crispie et al., 2008; Arroyo et al., 2010); (2) similarly to commensal bacteria, probiotic bacteria pass into the mammary gland (MG) via the external route; or (3) probiotic bacteria pass into the MG by the endogenous route via the mucosa associated lymphoid system, and thereby directly influence the composition of $\mathrm{MG}$ and milk microbiota.

Several studies have indicated the direct influence of consumed probiotics on milk microbiota. Orally administered probiotics have proven to be an effective alternative to treat mastitis versus the use of antibiotics (Jiménez et al., 2008; Arroyo et al., 2010). The probiotic strains Lactobacillus salivarius CECT5713 and Lactobacillus fermentum CECT5716 were able to modulate the human milk microbiome by decreasing the total bacterial count by $2 \log$ and replacing the mastitis-causing Staphylococcus by Lactobacillus. Both strains were also isolated from milk samples of women in the probiotic groups. The influence of probiotics on breast milk microbiota is also suggested by a study showing that maternal consumption of the probiotic strain Lactobacillus reuteri is associated with recovery of live $L b$. reuteri in breast milk (Abrahamsson et al., 2009). A Finnish group was able to isolate Lactobacillus rhamnosus isolates with a random amplified polymorphic DNA profile identical to the commercial strain $L b$. rhamnosus GG (LGG) from milk of Finnish women (Heikkilä and Saris, 2003); LGG is a frequently used probiotic strain in milk products in Finland (Salminen, 1996). Previous studies have shown that consumption of LGG during pregnancy and lactation affects the immune system of the MG (Prescott et al., 2008), which may change the colonization of the MG and, consequently, colonization of the infant's gut (Schultz et al., 2004).

Our pilot study on 2 breastfeeding mothers who consumed lyophilized probiotic strain Lactobacillus gasseri K7 (LK7) for 1 wk revealed the presence of DNA of the K7 strain not only in the feces and in the viable fecal lactobacilli consortium, but also in the milk of one mother (Matijašić et al., 2009). The LK7 strain is an isolate from a child's feces with established probiotic properties in vitro and in vivo (Rogelj and Matijašić, 2006). The gassericins K7A (GenBank: EF392861) and K7B (GenBank: AY307382) produced by this strain are among the first characterized bacteriocins of humanderived probiotic bacteria (Zorič Peternel et al., 2010) and have been used as targets for detection and quantification of LK7 in complex samples (Treven et al., 2013).

The aim of this study was to investigate the influence of consumption of probiotics LK7 and LGG during pregnancy and lactation on mice mesenteric lymph nodes (MLN), MG, and milk microbiota by culturedependent and culture-independent methods, including high-throughput 454-pyrosequencing. To evaluate possible endogenous transfer of probiotics to MG, presence of live LGG or LK7 was evaluated in different tissue samples. In addition, we gained important insights into the composition of MG and milk microbiota of mice, a frequently used model organism in the probiotics research.

\section{MATERIALS AND METHODS}

\section{Bacterial Strains and Growth Conditions}

A derivative of LK7 strain resistant to rifampicin $\left(\mathbf{L K} 7^{\mathbf{R}}\right)$ was obtained in the previous study of Bogovič Matijašić et al. (2007) and deposited in the microbial collection of Institute of Dairy Science and Probiotics, Biotechnical Faculty, University of Ljubljana, Slovenia. Eighteen-hour LK ${ }^{\mathrm{R}}$ culture in de Man, Rogosa, and Sharpe (MRS) broth (Merck, Darmstadt, Germany) with $125 \mu \mathrm{g} / \mathrm{mL}$ rifampicin $\left(\mathbf{M R S}^{\mathbf{R}}\right)$ and 18 -h LGG (originally obtained from Valio, Helsinki, Finland) culture in MRS broth were inoculated (1\% vol/vol) in MRS (without rifampicin) and incubated at $37^{\circ} \mathrm{C}$ in anaerobic conditions for $18 \mathrm{~h}$. Bacterial cultures were harvested by centrifugation at $3,500 \times g$ for 5 min at $4^{\circ} \mathrm{C}$ and washed twice with sterile PBS. The pellets were resuspended in $2 \mathrm{~mL}$ of sterile, reconstituted $(10 \%$ wt/vol) skim milk (Merck). Aliquots $(500 \mu \mathrm{L})$ were stored at $4^{\circ} \mathrm{C}$ for up to $6 \mathrm{~d}$. On the first and last days of storage, the viability of bacteria was determined by plating serial dilutions of bacterial suspensions on MRS agar plates, which were incubated anaerobically at $37^{\circ} \mathrm{C}$ for $48 \mathrm{~h}$.

\section{Animals}

All animal experiments were performed in accordance with institutional and European directives for research animal use and were approved by the Veterinary Administration of the Republic of Slovenia (approval number: 34401-17/2011/5). Fifteen male and 30 female 
FVB/NHanHsd (Harlan, Udine, Italy) mice, 7 to $10 \mathrm{wk}$ old, were housed at 20 to $21^{\circ} \mathrm{C}$ (50 to $70 \%$ humidity) on a 12-h light and 12-h dark cycle, fed ad libitum with a standard chow diet (Altromin 1320; Altromin, Lage, Germany) and sterilized water. To minimize the possibility of contamination of MG with mice feces, mice were housed in cages equipped with raised-bottom, wire mesh grids (Tecniplast, Buguggiate, Italy) on which the "mouse house" (Tecniplast) was fixed. The bottom side of the mouse house was closed with red plasticized cardboard. A sterile cotton pad (Nestlets, Plexx, Elst, the Netherlands) was placed into the mouse house to allow animals to make a nest. Female mice ( 5 per cage) and male mice (1 per cage) were acclimated for $14 \mathrm{~d}$ to the bottom-raised grids by gradually removing the bedding from fully covered grids. After $14 \mathrm{~d}$ of acclimation, 2 female mice were housed with 1 male overnight; the next morning, females with a vaginal plug [gestational day (GD) 0] were individually caged and randomized to experimental or control groups.

\section{Experimental Procedure}

From GD7 until the end of experiment, mice were orally fed with $200 \mu \mathrm{L}$ of reconstituted (10\% wt/vol) skim milk (control group, N) or $200 \mu \mathrm{L}$ of bacterial suspension of LGG (on average $4.1 \times 10^{8} \mathrm{cfu} / \mathrm{d}$, group $\mathbf{G}$ ), or $\mathrm{LK}^{\mathrm{R}}$ (on average, $3.6 \times 10^{8} \mathrm{cfu} / \mathrm{d}$, group $\mathbf{K}$ ) in skim milk. To ensure equal daily dosages, orogastric feeding needles (Eickemeyer, Tuttlingen, Germany) were used. Animals were weighed daily before treatment. To prevent bacterial contamination of nipples during milk sampling and animal dissections, on GD12, the abdomen and nipples were depilated using depilation crème (Weet, Reckitt Benckiser, Slough, UK) and sanitized with $70 \%$ ethanol. During the depilation procedure, mice were anesthetized with $1.5 \%$ isoflurane delivered using a dedicated vaporizer (Harvard Apparatus, Holliston, MA), added to a constant flow $(1 \mathrm{~L} / \mathrm{min})$ of 0.3:0.7 $\mathrm{O}_{2}: \mathrm{N}_{2} \mathrm{O}$ mix. The procedure was performed on a heating pad (Sanitas SHK18, Hans Dinslage, Uttenweiler, Germany) to prevent hypothermia.

\section{Sample Collection}

All sampling procedures were carried out in a laminar hood using sterile equipment and procedures. Four animals from each group were killed on $\mathrm{d} 3$ and $\mathrm{d} 8$ postpartum (PP). Milk and blood samples were collected just before mice were euthanized. Six to $8 \mathrm{~h}$ before milk sampling, dams were separated from their pups and mice fecal samples were collected, instantly frozen in liquid nitrogen, and stored at $-80^{\circ} \mathrm{C}$. Fifteen minutes before milking, mice were injected intraperi- toneally with $150 \mu \mathrm{L}$ of oxytocin (2 IU per animal; Sigma, St. Louis, MO). Mice were anesthetized with $1.5 \%$ isoflurane on a heating pad and their MG were massaged slightly to induce milk let-down. Nipples and abdomen area were cleaned with ethanol and the first drop of milk was wiped with cotton pad soaked in $70 \%$ ethanol. Milk was collected by manual expression into sterile glass Pasteur pipettes. Sample volumes ranged between 100 and $500 \mu \mathrm{L}$ per mouse. Milk samples were transferred to 1.5-mL Eppendorf microcentrifuge tubes, instantly frozen in liquid nitrogen, and stored at $-80^{\circ} \mathrm{C}$. Immediately after milking, with mice still under anesthesia, blood was collected by cardiac puncture into heparinized syringes (Multivette 600, Sarstedt, Nümbrecht, Germany), transferred to microcentrifuge tubes, and stored at $4^{\circ} \mathrm{C}$ until analyzed. After cardiac puncture, animals were killed using cervical dislocation and dissected to obtain MG and MLN. All tissue samples were collected into microcentrifuge tubes, instantly frozen in liquid nitrogen, and stored at $-80^{\circ} \mathrm{C}$ until homogenization. Then, MG and MLN were thawed, weighed, suspended in half-fold volume (for MG) or 10fold volume (for MLN) of sterile PBS and homogenized using an UltraTurrax homogenizer (IKA Werke GmbH, Staufen, Germany) under constant cooling on ice.

\section{Analysis}

Detection and Enumeration of Strains LGG and $L_{K} \boldsymbol{\gamma}^{R}$ in Mice Feces. Fecal samples were resuspended in 100-fold volume of sterile PBS. To detect live $\mathrm{LGG}, 100 \mu \mathrm{L}$ of suspension was plated on modified Rogosa agar plates supplemented with vancomycin $(50 \mu \mathrm{g} / \mathrm{mL})$ and nalidixic acid $(\mathbf{R V N} ; 40 \mu \mathrm{g} / \mathrm{mL})$. For selective detection of $\mathrm{LK} 7,100 \mu \mathrm{L}$ of suspension was plated on $\mathrm{MRS}^{\mathrm{R}}$ agar plates. Plates were incubated for $72 \mathrm{~h}$ at $37^{\circ} \mathrm{C}$ in anaerobic conditions. Grown colonies were rinsed from RVN and $\mathrm{MRS}^{\mathrm{R}}$ plates with $2 \mathrm{~mL}$ of sterile PBS, and genomic DNA from bacterial suspension was extracted using the Maxwell 16 Tissue DNA Purification kit (with Maxwell 16 instrument; Promega, Madison, WI) according to the manufacturer's protocol for isolation of genomic DNA from gram-positive bacteria. For the LGG strain-specific PCR, DNA extracted from RVN-rinsed bacterial suspension was used $(1 \mu \mathrm{L})$ as a template in a $25-\mu \mathrm{L}$ reaction volume. The LGG strain-specific PCR was performed as described previously (Ahlroos and Tynkkynen, 2009) by using end-point PCR with the forward primer 5'-CGCCCTTAACAGCAGTCTTCAAAT-3' and reverse primer 5'-ACGCGCCCTCCGTATGCTTAAACC-3', followed by agarose gel electrophoresis and SYBR Safe (Invitrogen, Waltham, MA) staining. For detection of the $\mathrm{LK} 7^{\mathrm{R}}$ strain, the target of PCR was a total gene cluster of 
gassericin K7A, a specific bacteriocin produced by LK7 (Rogelj and Matijašić, 2006). A PCR with specific gassericin K7A primers, GasA_2F (5'-GGATCATGTGGTAAAGGTGCAGTA-3') and GasA_2R (5'-TCCACTAGCAGTTTGTAGAACCAAT-3'), was performed as described previously (Treven et al., 2013). For a template, $1 \mu \mathrm{L}$ of DNA extracted from $\mathrm{MRS}^{\mathrm{R}}$-rinsed bacterial suspension was used in a $20-\mu \mathrm{L}$ reaction volume.

For quantification of probiotic strains in mice feces by real-time PCR, $1 \mathrm{~mL}$ of each 100-fold diluted sample was centrifuged at $14,000 \times g$ for 5 min at $4^{\circ} \mathrm{C}$, and genomic DNA from the pellet was extracted with Maxwell 16 Tissue DNA Purification kit (with Maxwell 16 instrument; Promega) according to the manufacturer's protocol for isolation of genomic DNA from gram-positive bacteria. Quantification of LGG was performed with strain-specific primers Lrhamn1 (5'-CAATCTGAATGAACAGTTGTC- $\left.3^{\prime}\right)$ and Lrhamn2 (5'-TATCTTGACCAAACTTGACG-3') (Brandt and Alatossava, 2003), applying the amplification program described by Dommels et al. (2009). Quantification of LK7 was performed with specific gassericin K7A primers GasA_2F, applying the amplification program described by Treven et al. (2013). Assays were performed on MX3000P instrument (Stratagene, Santa Clara, CA) in a $20-\mu \mathrm{L}$ volume containing $1 \times$ KAPA SYBR FAST Universal $2 \times$ qPCR Master Mix (Kapa Biosystems, Wilmington, MA), $0.4 \mu M$ concentrations of each specific primer for LGG or $0.2 \mu M$ concentrations of each specific primer for LK7 and 1 $\mu \mathrm{L}$ of half-fold dilution of the extracted genomic DNA for LGG or $1 \mu \mathrm{L}$ of 10 -fold dilution of the extracted genomic DNA for LK7. For quantitative analysis of the threshold cycle (with the Stratagene MX3000P system program), each sample was compared with a standard curve made from serial dilutions of the chromosomal DNA isolated from $1 \mathrm{~mL}$ of an 18 -h culture of LGG or LK7. Counts $(\mathrm{cfu} / \mathrm{mL})$ in the 18 -h culture were determined by plate count on MRS agar plates. All reactions were made in duplicate and subjected to melting curve analysis to establish the specificity of the amplification. Results were expressed as $\log _{10}$ cfu per gram of fecal sample, taking into account the dilution steps.

Detection of Strains $L G G$ and $L K^{r} \gamma^{R}$ in Blood, $M L N$, and $\boldsymbol{M G}$. Heparinized blood $(100 \mu \mathrm{L})$, homogenized MG $(100 \mu \mathrm{L})$, and MLN $(50 \mu \mathrm{L})$ were enriched for $24 \mathrm{~h}$ in $900 \mu \mathrm{L}$ of MRS broth at $37^{\circ} \mathrm{C}$. After the enrichment step, $100 \mu \mathrm{L}$ of suspension was plated on MRS and $\mathrm{MRS}^{\mathrm{R}}$ agar plates and incubated for $72 \mathrm{~h}$ at $37^{\circ} \mathrm{C}$ in anaerobic conditions. Grown colonies were rinsed from MRS and $\mathrm{MRS}^{\mathrm{R}}$ plates with $2 \mathrm{~mL}$ of sterile PBS, and genomic DNA from bacterial suspension was extracted using the Wizard Genomic DNA Purification Kit (Promega) according to the manufacturer's proto- col for isolation of genomic DNA from gram-positive bacteria. For LGG strain-specific PCR, DNA extracted from MRS-rinsed bacterial suspension was diluted 100fold in water and used $(1 \mu \mathrm{L})$ as a template in LGG strain-specific PCR as described in the previous section. For detection of $\mathrm{LK}^{\mathrm{R}}, 1 \mu \mathrm{L}$ of DNA extracted from $\mathrm{MRS}^{\mathrm{R}}$-rinsed bacterial suspension and 100-fold diluted in water was used in PCR specific for a total gene cluster of gassericin $\mathrm{K} 7 \mathrm{~A}$, as described in the previous section.

Extraction of DNA from Tissue Samples and Milk. Before DNA extraction, milk samples from the same group were thawed, pooled, and suspended in 1 $\mathrm{mL}$ of ice-cold PBS. Homogenized MG and MLN were thawed and suspended in $1 \mathrm{~mL}$ of ice-cold PBS. Suspensions were centrifuged at $14,000 \times g$ for $5 \mathrm{~min}$ at $4^{\circ} \mathrm{C}$. Supernatant and the top fat layer were discarded and the remaining fat was wiped from the microcentrifuge tube with sterile cellulose paper. The pellet was resuspended in $600 \mu \mathrm{L}$ of $50 \mathrm{~m} M$ EDTA containing $10 \mathrm{mg} / \mathrm{mL}$ lysozyme and $12.5 \mathrm{U} / \mathrm{mL}$ mutanolysin. The mixture was incubated at $37^{\circ} \mathrm{C}$ for $2 \mathrm{~h}$. After enzymatic lysis, the mixture was centrifuged at 14,000 $\times \mathrm{g}$ for 5 min at $4^{\circ} \mathrm{C}$ and the supernatant was discarded. The bacterial DNA was isolated from the pellets using the QIAamp DNA Stool Mini kit (Qiagen, Hilden, Germany) following the manufacturer's instructions. Cell lysis was further optimized by performing an additional step in which pellets were homogenized in $1.4 \mathrm{~mL}$ of ASL buffer (a stool lysis buffer; Qiagen) and sonicated (Soniprep 150; MSE Scientific Instruments, London, UK) with cooling on ice. The program of sonication was 3 cycles of $30-$ s sonication with a 15 -s pause. Due to the small quantities of bacterial DNA in samples, the procedure was further optimized by increasing the amount of supernatant used in the procedure of proteinase K (Qiagen) digestion (from 200 to $600 \mu \mathrm{L}$ ); consequently, the amount of supernatant pipetted on the DNA binding column was equally increased. Bound DNA was eluted from the column by washing twice with $100 \mu \mathrm{L}$ of AE buffer $(10 \mathrm{~m} M$ Tris-Cl, $0.5 \mathrm{~m} M$ EDTA, $\mathrm{pH}$ 9.0; Qiagen), rather than a single elution with 200 $\mu \mathrm{L}$. The purity and concentration of purified genomic DNA were assessed spectrophotometrically (NanoVue, GE Healthcare Life Sciences, Little Chalfont, UK) by measuring absorbance at $260 \mathrm{~nm}$.

Number of Bacterial 16S Ribosomal DNA Copies in MLN, MG, and Milk by Real-Time $\boldsymbol{P C R}$. The DNA for the real-time PCR standard curve was isolated from overnight bacterial culture of Bacteroides thetaiotaomicron DSM2079, which was cultured in M2 medium (Hobson, 1969) at $37^{\circ} \mathrm{C}$ under anaerobic conditions as described in Matijašić et al. (2014). Bacteria were enumerated by phase-contrast 
microscopy using Petroff-Hausser Counting Chamber (Hausser Scientific, Horsham, PA) according to the manufacturer's instructions. Estimated initial number of bacterial 16S ribosomal DNA (rDNA) copies in overnight culture was calculated by multiplying number of enumerated bacteria with $16 \mathrm{~S}$ rRNA operon copy numbers of $B$. thetaiotaomicron VP1-5482, according to the data available in the $\mathrm{rrnDB}$ database (http:// rrndb.mmg.msu.edu/search.php). Three-fold dilution series of DNA isolated directly from the 18-h culture were prepared and amplified by real-time PCR.

The PCR reaction was performed in a $20-\mu \mathrm{L}$ volume containing $1 \times$ KAPA SYBR FAST Universal $2 \times$ qPCR Master Mix (Kapa Biosystems), $0.2 \mu M$ concentrations of each specific primer, and $1 \mu \mathrm{L}$ of extracted genomic DNA, which was spectrophotometrically calibrated to $10 \mathrm{ng} / \mu \mathrm{L}$. Primers Eub338F (5'-ACTCCTACGGGAGGCAGCAG-3') and Eub518R (5'-ATTACCGCGGCTGCTGG-3') were specific for the V3 variable region of the bacterial $16 \mathrm{~S}$ rRNA coding genes and described previously (Fierer et al., 2005). Amplification was performed using an MX3000P instrument (Stratagene). The amplification program was $50^{\circ} \mathrm{C}$ for $2 \mathrm{~min}$ and $95^{\circ} \mathrm{C}$ for $2 \mathrm{~min}, 25$ cycles of $95^{\circ} \mathrm{C}$ for $1 \mathrm{~min}, 53^{\circ} \mathrm{C}$ for $30 \mathrm{~s}, 72^{\circ} \mathrm{C}$ for $1 \mathrm{~min}$, and finally $72^{\circ} \mathrm{C}$ for $1 \mathrm{~min}$. All reactions were made in duplicate and subjected to melting curve analysis to establish the specificity of the amplification. Correlation between cycle threshold (Ct) values and initial 16S copy number were determined by the MX3000P system's program (Stratagene). Reaction efficiency $(\mathrm{E}=103.7 \%)$ was calculated from the slope of the standard curve: $y=-3.233 \times \log (x)+37.12$; $\mathrm{R}^{2}=0.997$, as $\mathrm{E}=10^{-1 / \text { slope }}-1$. The window of linearity was between $7.28 \times 10^{3}$ and $9.09 \times 10^{5}$ copies. No signal above the detection threshold was obtained for the nontemplate control samples ( $\mathrm{Ct}>25)$.

Metagenomic Analysis. Before 16S rRNA gene amplification, $20 \mu \mathrm{L}$ of isolated DNA from the same group (4 samples) were pooled to gain $6 \mathrm{MLN}, 6 \mathrm{MG}$, and 6 milk samples. Pooling was necessary because the amounts of DNA obtained from each individual sample were not sufficient to allow construction of the library. Therefore, the DNA of the 4 samples is considered a pool of genomes throughout this work, and the data summarize the possible microbes and genes occurring in these microbial niches. The $16 \mathrm{~S}$ rRNA genes were amplified using a primer set corresponding to primers (Andersson et al., 2008) 5'-AGAGTTTGATCCTGGCTC-3' and 5'-ATTACCGCGGCTGCTGG-3'. These PCR primers target the V5 and V6 hypervariable $16 \mathrm{~S}$ rRNA region. The forward primer contained the sequence of the titanium A adaptor (5'-CCATCTCATCCCTGCGTGTCTCCGACTCAG-3') and a barcode sequence (pools of 8 samples). For each sample, a PCR mix of
$100 \mu \mathrm{L}$ was prepared containing $1 \times$ PCR buffer, $2 \mathrm{U}$ of KAPA HiFi Hotstart polymerase blend and deoxynucleotide triphosphates (dNTP; Kapa Biosystems), $300 \mathrm{n} M$ concentrations of primers (Eurogentec, Liège, Belgium), and $60 \mathrm{ng}$ of genomic DNA. Thermal cycling consisted of initial denaturation at $95^{\circ} \mathrm{C}$ for $5 \mathrm{~min}$, followed by 25 cycles of denaturation at $98^{\circ} \mathrm{C}$ for 20 $\mathrm{s}$, annealing at $56^{\circ} \mathrm{C}$ for $40 \mathrm{~s}$, and extension at $72^{\circ} \mathrm{C}$ for $20 \mathrm{~s}$, with a final extension of $5 \mathrm{~min}$ at $72^{\circ} \mathrm{C}$. The PCR product $(3 \mu \mathrm{L})$ was added to a new PCR mix (identical to the first round of PCR) for the nested PCR of 15 cycles. Amplicons were visualized on $1 \%$ agarose gels using GelGreen Nucleic Acid gel stain in $1 \times$ Tris-acetate-EDTA (Biotium, Hayward, CA) and were cleaned using the Wizard SV Gel and PCR Cleanup System (Promega) according to the manufacturer's instructions.

Amplicon DNA concentrations were determined using the Quant-iT PicoGreen dsDNA reagent and kit (Life Technologies, Carlsbad, CA) following the manufacturer's instructions. Assays were carried out using 2 $\mu \mathrm{L}$ of cleaned PCR product in a total reaction volume of $200 \mu \mathrm{L}$ in black, 96-well microtiter plates. Following quantitation, cleaned amplicons were combined in equimolar ratios into a single tube. The final pool of DNA was eluted in a volume of $100 \mu \mathrm{L}$ nucleasefree water, purified using Agencourt Ampure XP purification systems according to the manufacturer's instructions (Agencourt Biosciences Corp./Beckman Coulter, Brea, CA) and resuspended in $100 \mu \mathrm{L}$ of $1 \times$ Tris-EDTA. The concentration of the purified pooled DNA was determined using the Quant-iT PicoGreen dsDN reagent and kit (Life Technologies) following the manufacturer's instructions. Pyrosequencing was carried out using primer A on a 454 Life Sciences Genome Sequencer FLX instrument (Roche, Basel, Switzerland) following titanium chemistry.

Despite the nested PCR approach, in 5 of 6 milk samples, the amount of amplified 16S rRNA genes was insufficient for further analysis. The only fully assayed milk sample was in part from an animal with suspected mastitis (based on the milk and MG results), which could not be considered as representative and therefore was omitted from the results. The sequences were assigned to samples according to sample-specific barcodes. This allowed us to collect FASTA-formatted files containing an average $( \pm \mathrm{SD})$ of $16,219 \pm 8,927$ sequences per sample. Sequences were then checked for the following criteria: (1) almost perfect match with barcode and primers; (2) length of at least 240 nucleotides (barcodes and primers excluded); and (3) no more than 2 undetermined bases (denoted by N). By "almost perfect match," we mean that one mismatch, deletion, or insertion is allowed in the barcode, and the same 
for the primer. Each sequence originating from pyrosequencing and passing quality control was assigned to a family by the RDP classifier (v. 2.1; http://rdp.cme. msu.edu) with confidence estimate $>80 \%$. The Chao1 richness estimate (Chao, 1984) and nonparametric Shannon index (Chao and Shen, 2003) for species group [operational taxonomic unit (OTU) distance of 0.03] was done through the Mothur package (Schloss et al., 2009).

\section{Statistical Analysis}

Statistical analysis was performed with SigmaPlot 11.0 (Systat Software; SPSS Inc., Chicago, IL). Data from real-time PCR analysis were tested for equal variance $(P>0.05)$ and normality (Shapiro-Wilk's normality test; $P>0.05$ ) before performing a 2-way ANOVA, followed by all pairwise Holm-Sidak multiple comparison procedures. Values for copies per milligrams of tissue of MLN were log-transformed before analysis to pass the normality test. The threshold for statistical significance was set as $P \leq 0.05$.

\section{RESULTS}

\section{Presence of Live LGG and LK7 in Fecal and Tissue Samples}

Throughout the experiment period, no noticeable behavioral or activity changes were observed in mice and no illness or death occurred. We observed no treatment-related difference in any animal's BW gain (data not shown).

Presence of LGG and LK7 stains in feces was examined by strain-specific PCR using genomic DNA from suspensions of bacterial colonies grown on RVN and $\mathrm{MRS}^{\mathrm{R}}$ plates and by strain-specific real-time PCR using genomic DNA extracted directly from feces (Table 1). In 5 of 8 samples (d 3 and $8 \mathrm{PP}$ ) from the LGG group and in 5 of 8 samples (d 3 and $8 \mathrm{PP}$ ) from the LK7 group, more than $1 \times 10^{3}$ of live LGG or LK7 bacterial cells were detected, respectively. Probiotic count, as determined by strain-specific real-time PCR, ranged from 4.1 to $4.9 \log _{10} \mathrm{cfu} / \mathrm{g}$ of feces in LGGpositive samples (detection limit: $1.028 \times 10^{4} \mathrm{cfu} / \mathrm{g}$ ) and from 6.1 to $6.5 \log _{10} \mathrm{cfu} / \mathrm{g}$ of feces in LK7-positive samples (detection limit: $1.424 \times 10^{6} \mathrm{cfu} / \mathrm{g}$ ). No LGG or LK7 were detected by PCR or real-time PCR in control groups.

Blood, MLN, and MG were also examined for the presence of live LGG and LK7. After the enrichment step, 3 blood samples, 18 MLN samples, and 2 MG samples were culture-positive on MRS plates (Table 2), which indicated the presence of live lactic acid bacteria (LAB). However, LGG and LK7 strains could not be detected by strain-specific PCR in suspensions of bacterial colonies grown on $\mathrm{MRS}^{\mathrm{R}}$ and MRS.

\section{Total Bacterial 16S rDNA Load}

To compare the total bacterial load between treatments we assessed the number of $16 \mathrm{~S}$ rDNA copies (V3

Table 1. The presence of Lactobacillus rhamnosus GG (LGG) and rifampicin-resistant Lactobacillus gasseri $\mathrm{K} 7$ (LK7) strains in fecal samples determined by strain-specific PCR and real-time PCR

\begin{tabular}{lccccc}
\hline & \multicolumn{2}{c}{ LGG } & & \multicolumn{2}{c}{ LK7 } \\
\cline { 2 - 3 } \cline { 5 - 6 } Sample $^{1}$ & Viable $^{2}$ & Count $^{3}$ & & Viable $^{2}$ & Count $^{3}$ \\
\hline N3 & ND $^{4}$ & ND & & ND & ND \\
N8 & ND & ND & & ND & ND \\
G3 & $4 / 4$ & $4.52 \pm 0.25(3)$ & & ND & ND \\
G8 & $1 / 4$ & $4.66(1)$ & ND & & ND \\
K3 & ND & ND & & $4 / 4$ & $6.33 \pm 0.09(3)$ \\
K8 & ND & ND & & $1 / 4$ & ND \\
\hline
\end{tabular}

${ }^{1}$ Samples are designated as follows: $\mathrm{N}=$ control group, $\mathrm{G}=$ group fed with Lactobacillus rhamnosus $\mathrm{GG}, \mathrm{K}=$ group fed with rifampicin-resistant Lactobacillus gasseri $\mathrm{K} 7 ; 3$ and 8 indicate 3 and $8 \mathrm{~d}$ postpartum, respectively.

${ }^{2}$ For LGG viable counts, fecal suspensions (1,000-times diluted) were plated on modified Rogosa agar plates supplemented with vancomycin $(50 \mu \mathrm{g} / \mathrm{mL})$ and nalidixic acid $(40 \mu \mathrm{g} / \mathrm{mL})$ and the presence of viable LGG was determined by strain-specific PCR. For LK7 viable counts, fecal suspensions (1,000-times diluted) were plated on de Man, Rogosa, and Sharpe agar plates supplemented with rifampicin $(125 \mu \mathrm{g} / \mathrm{mL})$ and the presence of viable LK7 was determined by strain-specific PCR. Data are presented as number of LGG- or LK7-positive samples/number of tested fecal samples.

${ }^{3}$ Counts are presented as average $\log _{10}$ cfu equivalents/g of feces \pm SEM, determined by strain-specific real-time PCR. The number of samples on which the averages are based is given in parentheses.

${ }^{4}$ Not detected. 
Table 2. Number (no. of positive cultures/no. of tested tissues) of de Man, Rogosa, and Sharpe culturepositive samples from blood, mesenteric lymph nodes (MLN), and mammary glands (MG)

\begin{tabular}{lllllll}
\hline & \multicolumn{7}{c}{ Sample $^{1}$} \\
\cline { 2 - 7 } Item & N3 & G3 & K3 & N8 & G8 & K8 \\
\hline Blood & $0 / 4$ & $1 / 4$ & $1 / 4$ & $0 / 4$ & $1 / 4$ & $0 / 4$ \\
MLN & $2 / 4$ & $4 / 4$ & $2 / 4$ & $3 / 4$ & $3 / 4$ & $4 / 4$ \\
MG & $1 / 4$ & $1 / 4$ & $0 / 4$ & $0 / 4$ & $0 / 4$ & $0 / 4$ \\
\hline
\end{tabular}

${ }^{1}$ Samples are designated as follows: $\mathrm{N}=$ control group, $\mathrm{G}=$ group fed with Lactobacillus rhamnosus $\mathrm{GG}, \mathrm{K}=$ group fed with rifampicin-resistant Lactobacillus gasseri K7; 3 and 8 indicate 3 and 8 d postpartum, respectively.

region) per milligram of MLN, MG, or milk, as shown in Figure 1. Application of LGG and LK7 statistically increased the total bacterial $16 \mathrm{~S}$ rDNA load in MLN compared with the control group at both sampling times. On d 8 PP, MLN from both probiotic groups had a higher bacterial load compared with d $3 \mathrm{PP}$, although only the bacterial load in the LGG group was statistically significant. In $\mathrm{MG}$, no statistical significance was observed between control and probiotic groups; however, both probiotics increased the total bacterial $16 \mathrm{~S}$ rDNA load. In contrast to MLN, the number of bacterial 16S rDNA copies in MG was lower on d 8 PP compared with those from d 3 PP. Because the amount of bacterial DNA in individual samples of milk was extremely low, milk samples were pooled before DNA isolation. Because milk measures are single points, these results cannot be considered as valid trends for the tested variables. However, the results show that the bacterial load was $2 \log$ lower in tested milk samples compared with MG and did not completely resemble the results from MG (Supplementary Figure S1; http:// dx.doi.org/10.3168/jds.2014-8519).

\section{Metagenomic Analysis of 16S rDNA from MLN and MG}

High-throughput sequencing of the V5 and V6 hypervariable $16 \mathrm{~S}$ rRNA gene region performed on pooled DNA of the 4 parallel samples of MLN and MG generated a total of 114,549 quality-filtered sequence reads with an average of 9,545 sequences per sample (range 3,368-24,268). Using the Ribosomal Database Project Classifier (http://rdp.cme.msu.edu), sequences were assigned to the closest related taxa with a similarity threshold of $80 \%$. Nine bacterial phyla were found, with $>99 \%$ of sequences assigned to Proteobacteria, Bacteroidetes, or Firmicutes (Figure 2 and Supplementary Table S1; http://dx.doi.org/10.3168/jds.2014-8519). The highest relative variation between groups was observed for Firmicutes, where the abundance in MLN samples from the LGG group was highest on d 3 PP and lowest on d $8 \mathrm{PP}$. Both probiotic groups had a
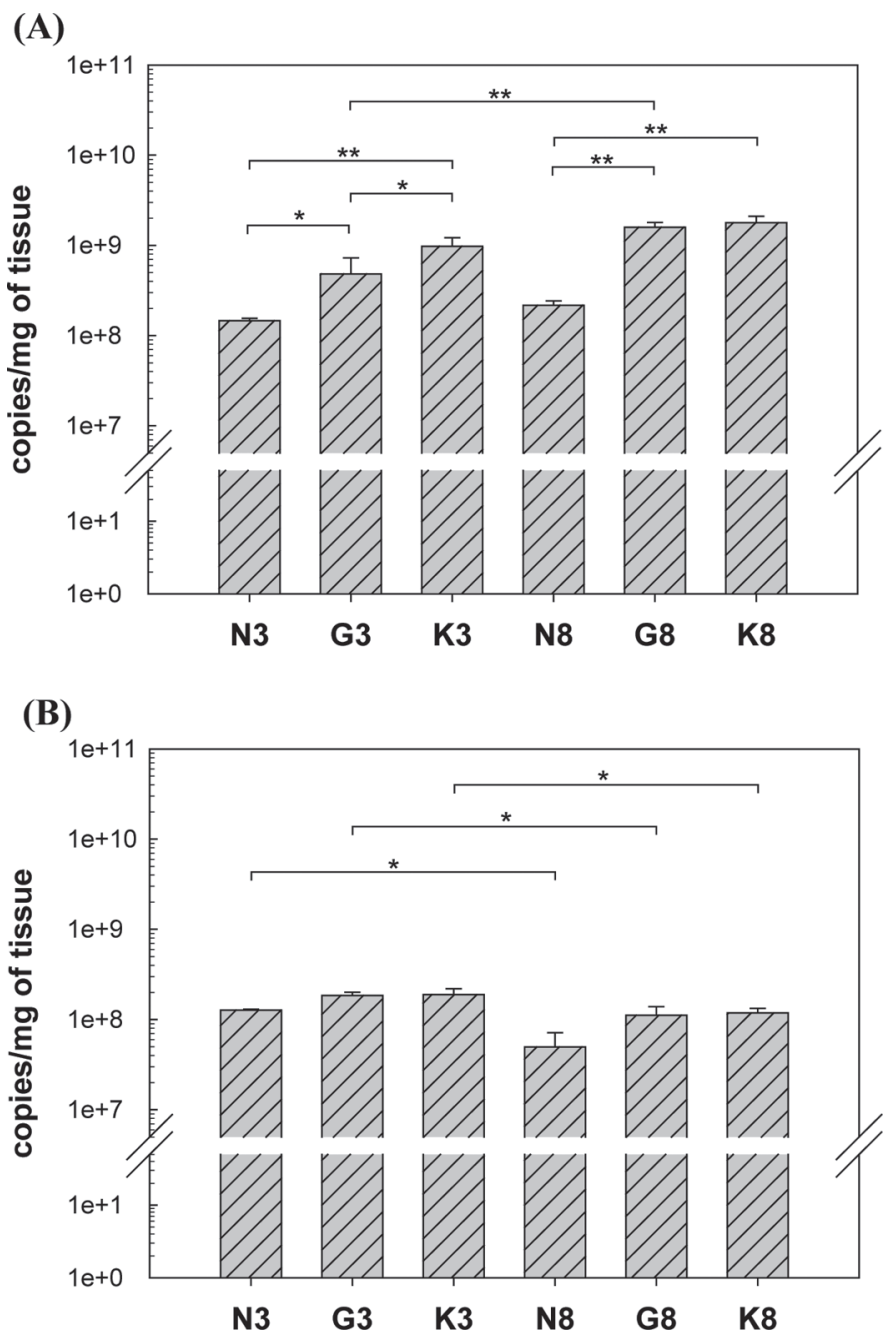

Figure 1. Number of bacterial $16 \mathrm{~S}$ ribosomal DNA copies (V3 region) per milligram of mesenteric lymph nodes (A) and mammary glands (B). Samples are designated as follows: $\mathrm{N}=$ control group, $\mathrm{G}$ = group fed with Lactobacillus rhamnosus $\mathrm{GG}, \mathrm{K}=$ group fed with rifampicin-resistant Lactobacillus gasseri K7; 3 and 8 indicate 3 and 8 d postpartum, respectively. Results are shown as the mean values of 4 measurements \pm SEM. Values for copies/mg of tissue of mesenteric lymph nodes were log-transformed before analysis to pass normality test (Shapiro-Wilk's normality test; $P>0.05$ ). Differences were evaluated with 2-way ANOVA, followed by all pair-wise Holm-Sidak multiple comparison procedures and are shown with horizontal lines $\left({ }^{*} P\right.$ $\left.<0.05 ;{ }^{* *} P<0.01\right)$. 
(A)
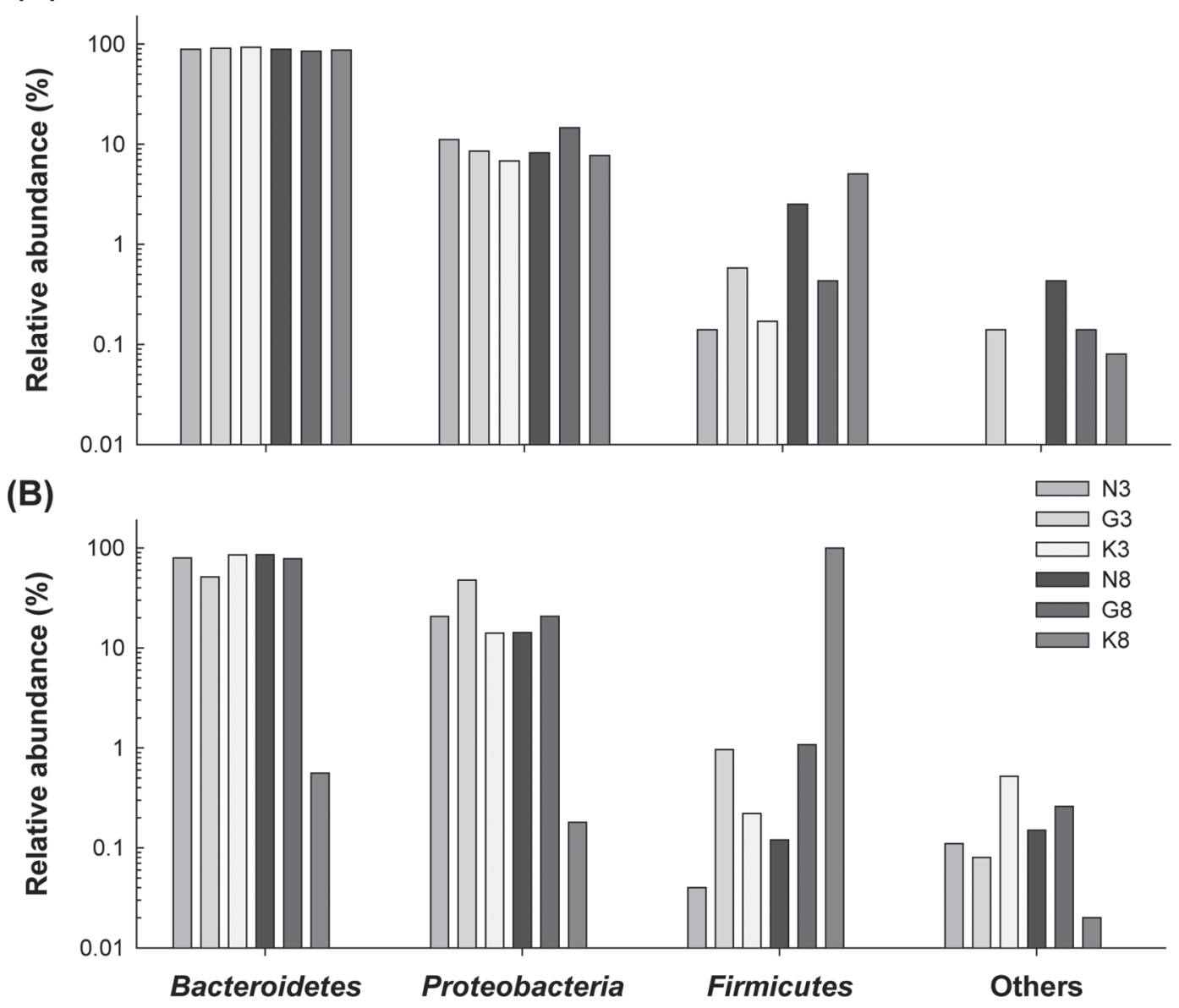

Figure 2. Relative $16 \mathrm{~S}$ rRNA gene abundances detected in mesenteric lymph nodes (A) and mammary gland (B) at the phylum level using pyrosequencing. Only phyla detected in all samples are shown. Parallel samples $(\mathrm{n}=4)$ from each group were pooled before sequencing. Samples are designated as follows: $\mathrm{N}=$ control group, $\mathrm{G}=$ group fed with Lactobacillus rhamnosus $\mathrm{GG}, \mathrm{K}=$ group fed with rifampicin-resistant Lactobacillus gasseri K7; 3 and 8 indicate 3 and 8 d postpartum, respectively.

higher abundance of Firmicutes in MG on both sampling days.

Six families (Flavobacteriaceae, Pseudomonadaceae, Sphingobacteriaceae, Caulobacteraceae, Xanthomonadaceae, Alcaligenaceae) represented more than 95\% (median $98.19 \%$ ) of the reads in each sample (Figure 3 and Supplementary Table S2; http://dx.doi.org/10.3168/ jds.2014-8519), and the most abundant genera (Flavobacterium, Elizabethkingia, Pseudomonas, Pedobacter, Sphingobacterium, Brevundimonas, Stenotrophomonas, Rhodanobacter, Bordetella) were representatives of aerobic, gram-negative bacteria (Supplementary Table S3; http://dx.doi.org/10.3168/jds.2014-8519), which are usually found in marine sediments, water, and soil. The rest of the reads $(0.72 \%$ of all family-assigned reads) were mostly assigned to representatives of anaerobic and facultative aerobic gram-positive bacteria. Gut-associated obligate anaerobes such as Bacteroidaceae, Ruminococcaceae, Clostridiaceae, Lachnospiraceae, and Porphyromonadaceae were found in MLN as well as in MG (Supplementary Table S2; http://dx.doi. org/10.3168/jds.2014-8519). The highest relative variation between groups at a family level was observed for Streptococcaceae and Lactobacillaceae. It is noteworthy that Lactobacillaceae were present only in MG of probiotic groups. In MG from the K8 group, predominance of Streptococcaceae was observed, caused by overgrowth of Streptococcus in one of the samples. The overgrowth of bacteria in one of the K8 MG was also confirmed when the sample was plated on blood agar (data not shown). A detailed view of LAB genera (Table 3) revealed that both probiotic groups at both sampling times had greater abundance of the LAB group in MG, mostly due to a higher number of reads assigned to Lactobacillus and Streptococcus. The G8 group also contained bifidobacterial reads $(0.24 \%)$, which are not LAB but are believed to be very important in fecal microbiota development. 
To assess bacterial diversity, the Chao1 richness estimate (Chao, 1984) and nonparametric Shannon index (Chao and Shen, 2003) for species group (OTU distance of 0.03) were calculated and are presented in Figure 4. Except for the K8 group, which was skewed due to the overgrowth of Streptococcus in one sample, MLN from probiotic groups had a lower Chao1 richness estimate and a higher Shannon diversity index compared with the control groups. In contrast, a higher Chao1 richness index was observed in MG from probiotic groups, and only MG from the LGG group (G3 and G8) had a higher Shannon diversity index than the control groups.

\section{DISCUSSION}

The aim of this study was to examine effects of probiotics LGG and LK7 on MLN and MG microbiota of pregnant and lactating mice. Furthermore, the endogenous transfer of administered probiotics from gut to MG was evaluated, because recent studies have shown that this endogenous route, via the entero-mammary pathway, could be one way for translocation of some bacterial species into MG (Perez et al., 2007; Fernandez et al., 2013).

Contamination of milk samples with bacteria from the surrounding skin is often reported in humans and animals (Quigley et al., 2013). To limit the external contamination of the MG, the mice were housed on raised-bottom, wire mesh grids, and the surfaces of their abdomen and nipples were depilated on GD12 (see Materials and Methods section). Naturally, mice keep their nests clean and excrete urine and feces outside the nest box (Blum et al., 1999), which was confirmed in our study.

An important prerequisite of probiotics is that the bacteria of interest at least transiently colonize the intestine of the respective animals. It was shown previously that both probiotic strains (LGG and LK7) can survive passage through the intestinal tract of mice after oral administration of probiotics (Blümer et al., 2007; Sagaya et al., 2014). In our study, we confirmed the presence of viable LGG and LK7 strains $\left(>1 \times 10^{3}\right.$ cfu/g) by strain-specific PCR in all samples from $\mathrm{d} 3$ $\mathrm{PP}$ and in one sample from d 8 PP (Table 1). Results from real-time PCR confirmed detectable levels of LGG in 4 samples from the LGG group and detectable levels of LK7 in 3 samples from the LK7 group. Because the detection limits were higher for the strain-specific real-time PCR assays than for the culture-dependent method, where samples were spread on agar plates, not all culture-positive samples were confirmed by real-time PCR. As expected, LGG and LK7 were recovered and detected only from LGG- and LK7-treated mice.
Several independent studies have suggested that probiotic bacteria orally administered during pregnancy and lactation can directly influence MG and milk microbiota by increasing the presence of corresponding genera or strains in collected milk samples (Heikkilä and Saris, 2003; Abrahamsson et al., 2009; Arroyo et al., 2010; Nasiraii et al., 2011). In our study, despite the presence of live LAB in all 3 types of samples (blood, MLN, and MG; Table 1), no cultivable LGG or LK7 or their DNA were observed in collected samples. For the detection of corresponding DNA isolated directly from the tissue samples, the limit of detection was $100 \mathrm{cfu} /$ mg (data not shown). The limit of detection for live LGG and LK7 after the enrichment step was $<1 \mathrm{cfu/}$ $\mathrm{mg}$ of tissue. Because this method was based on detecting the specific DNA isolated from grown colonies, the presence of dead or live but uncultivable bacterial cells could lead to a higher detection limit and to falsenegative results.

According to Perez et al. (2007), bacteria can migrate from MLN to MG during d $1 \mathrm{PP}$. However, it is not known when this process starts or ends and what factors limit that period (Jeurink et al., 2013). Our inability to detect DNA or live LGG and LK7 could be the consequence of the missed "window of opportunity" because we sampled only on d 3 and 8 PP. If migration from MLN to MG is indeed confined to a very narrow time window, a much larger scale study should be conducted involving daily sampling during pregnancy or lactation. Alternatively, it is possible that LGG or LK7 do not translocate in the manner shown for the 3 probiotic bifidobacteria strains with proven beneficial effects and safe use in nutrient formulas for infants and toddlers (Abe et al., 2010). Therefore, although no live LK7 or LGG were found in MG or milk, the observed beneficial effects of LGG or LK7 could be due to their beneficial action, as discussed below.

The assessment of total bacterial 16S rDNA load by real-time PCR revealed a greater number of copies of $16 \mathrm{~S} \mathrm{rDNA} / \mathrm{mg}$ of MLN in both probiotic groups at both sampling times (Figure 1A). Translocation of bacteria from gut to MLN in healthy adult mice is a rare but normal event that relies on the permeability of epithelium and stimulation of the immune system (Wells et al., 1988). Several studies have shown that different LAB and potential probiotics can stimulate the immune system and translocate to MLN of healthy adult mice without causing systemic infection (Zhou et al., 2000; Maragkoudakis et al., 2009; Kandasamy et al., 2011). Most likely, the application of probiotics resulted in an increased activation of the immune system (Gorbach, 2000; Sagaya et al., 2014) and increased sampling of beneficial commensal bacteria from the intestinal lu- 
(A)

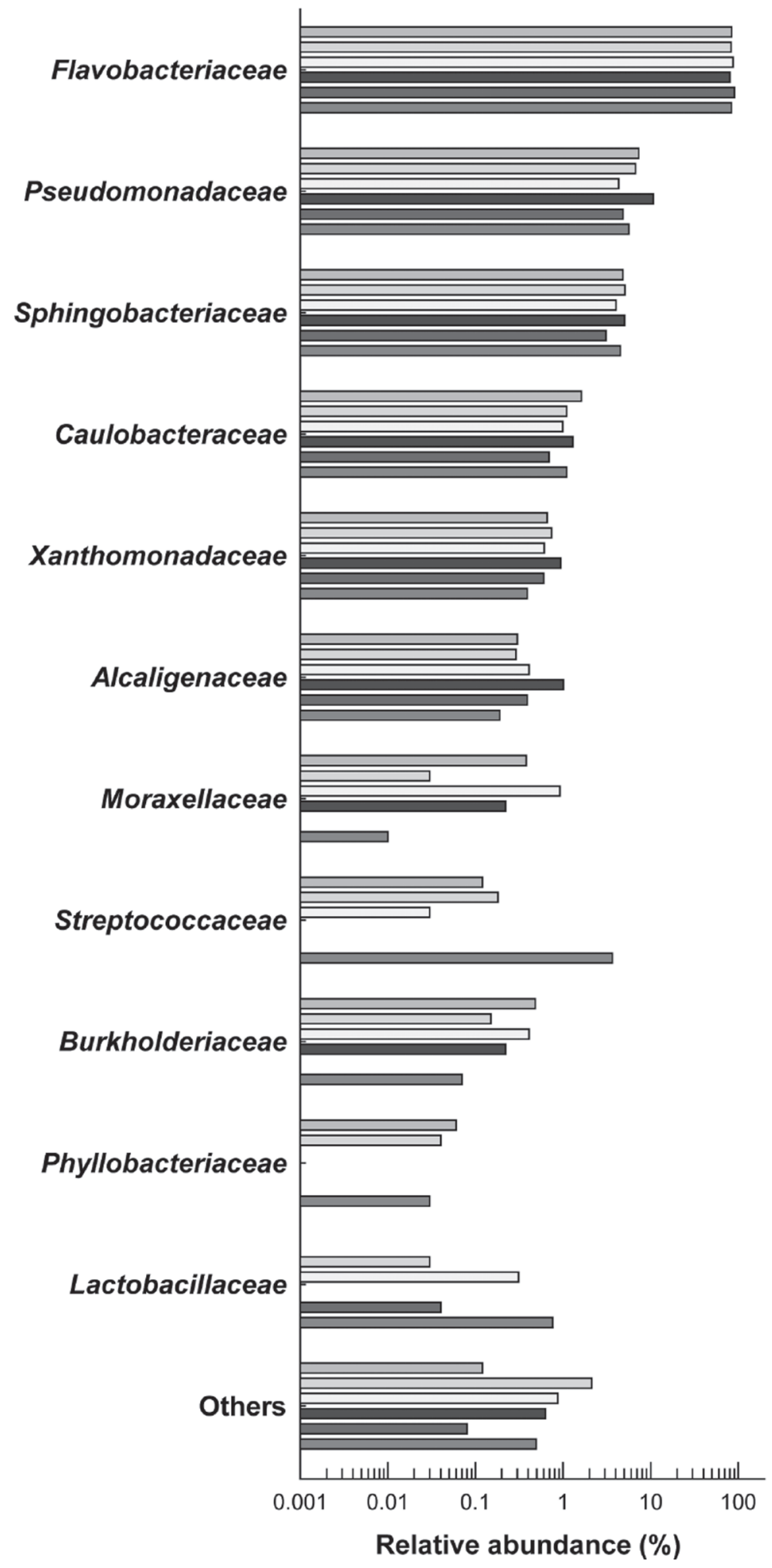

(B)

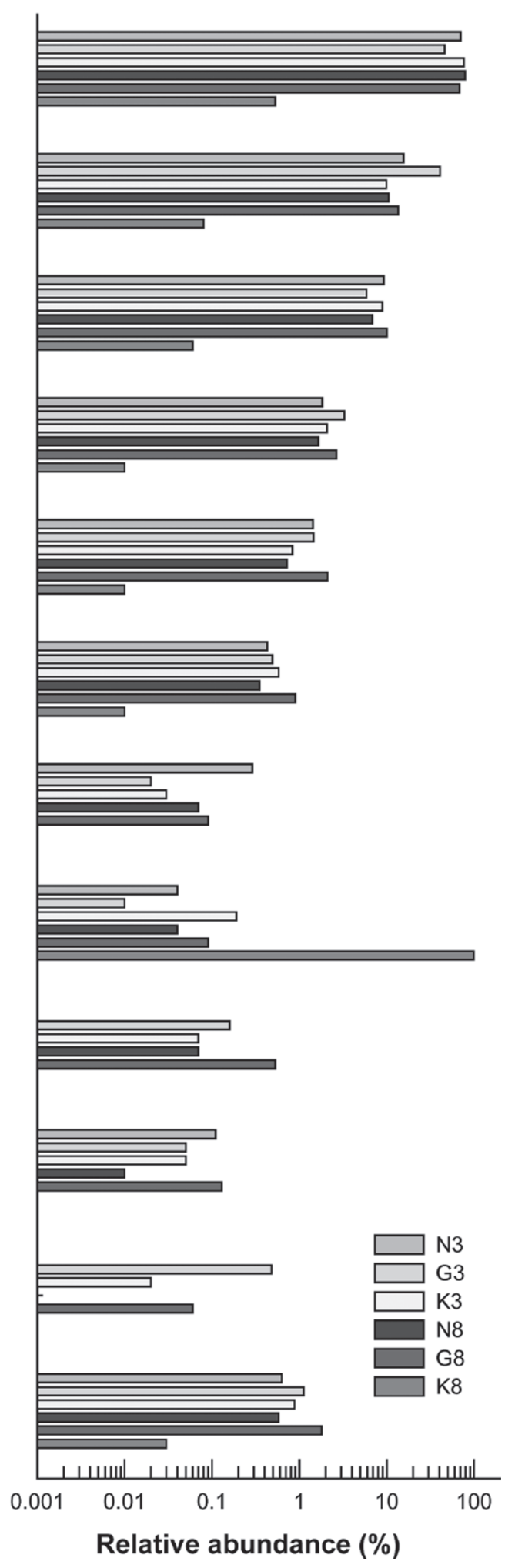

Figure 3. Relative 16S rRNA gene abundances detected in mesenteric lymph nodes (A) and mammary gland (B) at the family level using pyrosequencing. Only families detected at relative abundance $\geq 0.5 \%$ in at least one ecosystem are reported. Parallel samples $(\mathrm{n}=4)$ from each group were pooled before sequencing. Samples are designated as follows: $\mathrm{N}=$ control group, $\mathrm{G}$ = group fed with Lactobacillus rhamnosus GG, $\mathrm{K}=$ group fed with rifampicin-resistant Lactobacillus gasseri K7; 3 and 8 indicate 3 and 8 d postpartum, respectively. 
Table 3. Number of reads detected in mesenteric lymph nodes (MLN) and mammary glands (MG) that were assigned to different genera of lactic acid bacteria (LAB)

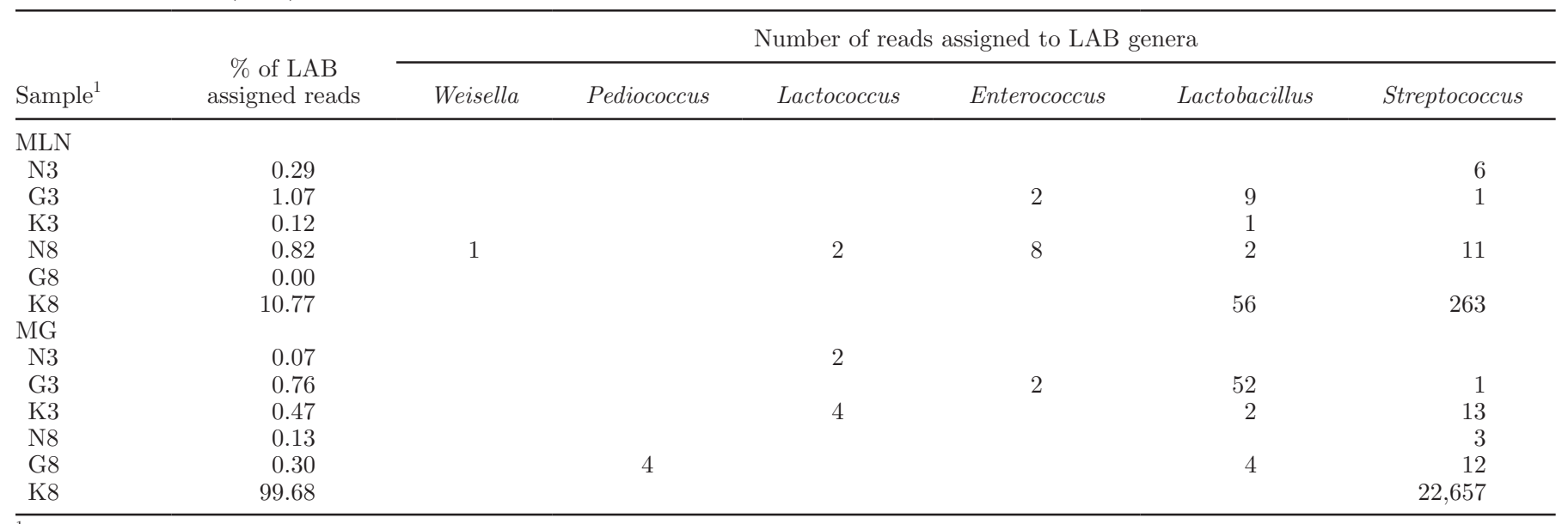

${ }^{1}$ Parallel samples $(\mathrm{n}=4)$ from each group were pooled before sequencing. Samples are designated as follows: $\mathrm{N}=$ control group, $\mathrm{G}=$ group fed with Lactobacillus rhamnosus GG, K = group fed with rifampicin-resistant Lactobacillus gasseri K7; 3 and 8 indicate 3 and 8 d postpartum, respectively.

men. Moreover, in pregnancy and lactation there could be an increased frequency of translocation of bacteria to MLN and migration of bacterial cells to MG via the entero-mammary pathway (Perez et al., 2007). In addition, as in MLN, a trend of higher bacterial DNA load in both probiotic groups was observed in MG (Figure 1B). According to Martín et al. (2003), bacteria in MG probably form a biofilm on the mammary areola, inside the mammary duct system, or both. This could explain the differences in bacterial DNA load between MG and milk samples (Figure 1B and 1C) and the lower bacterial load in MG on d 8 PP compared with d 3 PP. On d $8 \mathrm{PP}$, samples of MG had a higher proportion of milk, which had fewer bacterial cells compared with MG tissue, resulting in fewer copies per milligram. Our results of increased total bacterial load in both probiotic treatment groups are most likely a result of probiotics affecting the host (mucosal) immune homeostasis, changing its capacity to shape the microbial population in the intestine and other tissues.

Metagenomic sequence analysis of bacterial $16 \mathrm{~S}$ rDNA at all 3 levels (phylum, family, and genus) revealed that most sequences ( $>95 \%$ of assigned reads) were derived from contaminating bacterial DNA present in reagents. It is very unlikely that all samples of MG or MLN contained such large and similar proportions of aerobic gram-negative bacteria, which are characteristic of environmental and water samples. The presence of contamination is usually more pronounced in samples with very small amounts of target DNA (Teletchea et al., 2005; Champlot et al., 2010). The most commonly occurring genera due to contamination are Pseudomonas, Stenotrophomonas, Salmonella, Shigella, Phylobacterium, Arthrobacter, Corynebacte- rium, and other, mostly gram-negative, aerobic bacteria (Hughes et al., 1994; Tanner et al., 1998; Grahn et al., 2003; Spangler et al., 2009). It is noteworthy that in metagenomic sequencing, the occurrence of contaminating sequences is directly correlated with the concentration of target DNA in samples (Willner et al., 2012; Salter et al., 2014), and small amounts of target DNA can lead to overrepresentation of contaminating sequences (Biesbroek et al., 2012; Lazarevic et al., 2014). Taking into account the regression equation of Willner et al. (2012), theoretically, in $0.06 \mathrm{ng}$ of target DNA (about $6.4 \times 10^{4}$ copies), about $91 \%$ of all the detected sequences could be a result of contamination. We did not pursue a follow-up study to determine which reagents contributed the most contaminating bacterial DNA (our own reagents or those from kits, those of the sequencing company performing the pyrosequencing, or both). Our study, like others, emphasizes the need to control such contamination, perhaps by using molecular biology-grade reagents and DNA sequencing services certified as using reagents free of nucleic acids. Nevertheless, similar proportions of contaminating species were found across treatments, and the highest relative variation between groups was observed for the phylum Firmicutes, especially for the Streptococcaceae and Lactobacillaceae families. Because representatives of these taxa are not common contaminants in PCR reactions or usually present in water and soil samples, we believe that the results can be interpreted as being a consequence of probiotic treatments.

Administration of both probiotics during pregnancy and lactation had the greatest effect on the abundance of Firmicutes in MLN and MG (Figure 2). In MLN, the effect was noticeable only in the LGG group, whereas 
(A)

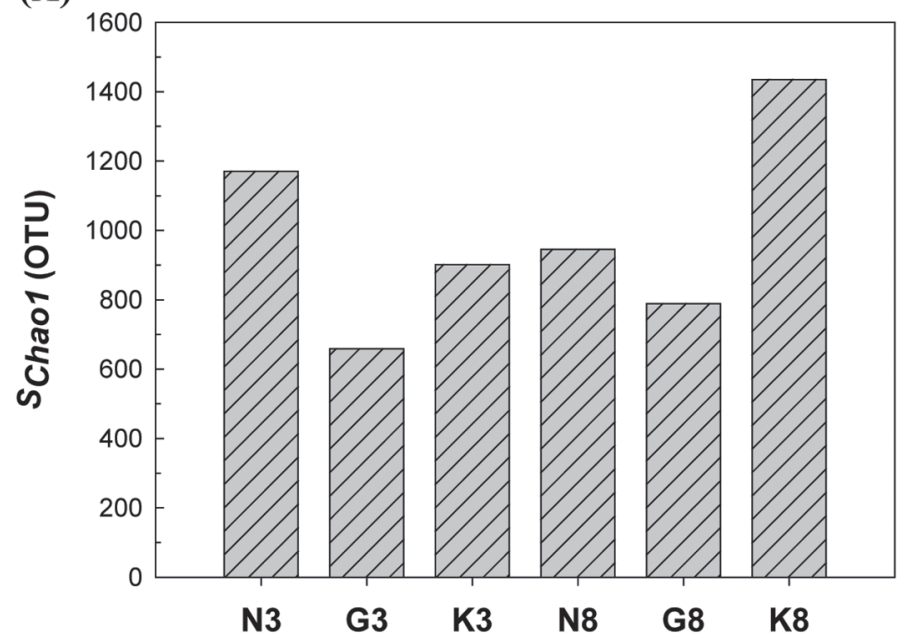

(C)

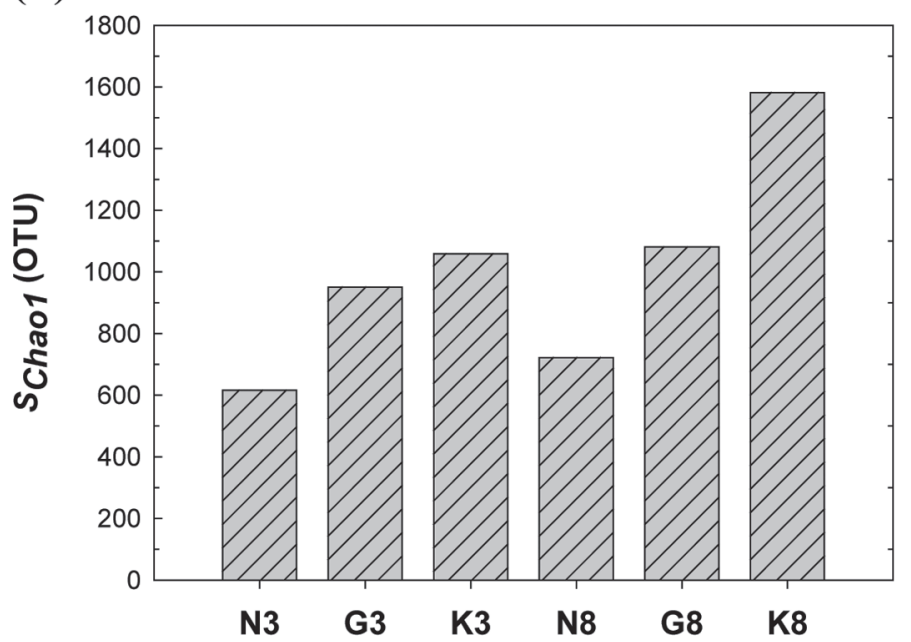

(B)

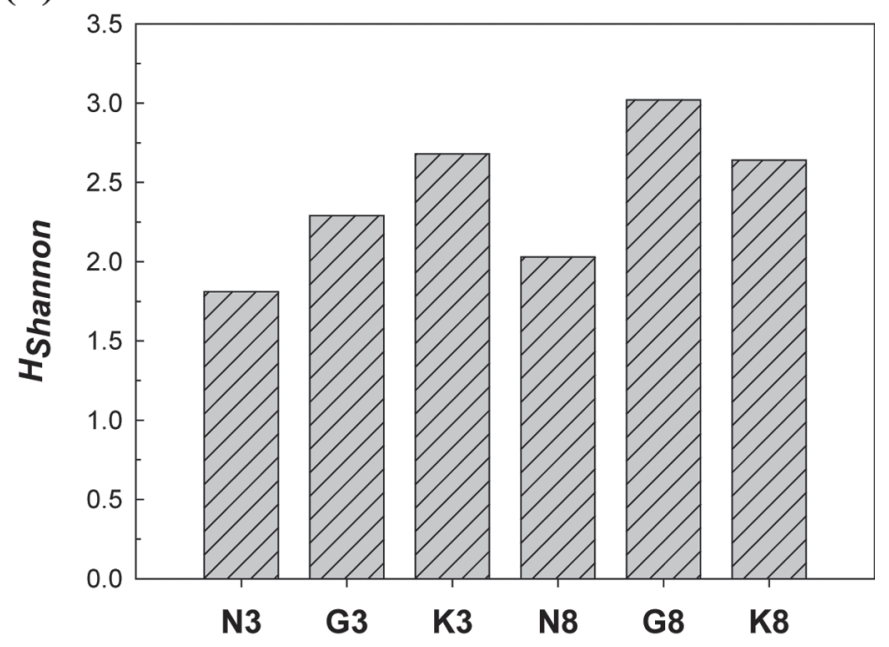

(D)

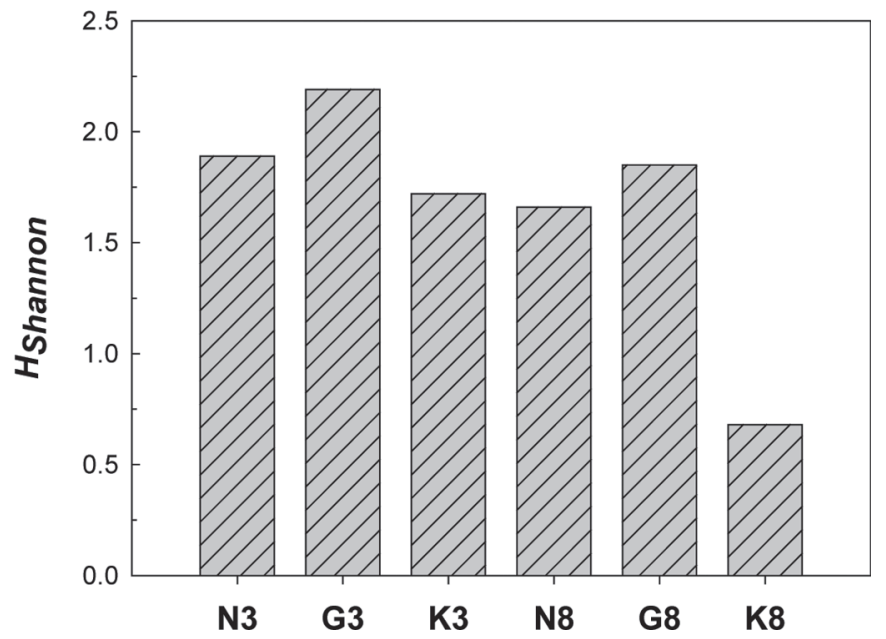

Figure 4. Chao1 richness estimate $\left(\mathrm{S}_{\text {Chao } 1}\right)$ and nonparametric Shannon diversity index $\left(\mathrm{H}_{\text {Shannon }}\right)$ for species group [operational taxonomic unit (OTU) distance of 0.03$]$ in mesenteric lymph nodes (A, B) and mammary glands (C, D). Parallel samples $(\mathrm{n}=4)$ from each group were pooled before sequencing. Samples are designated as follows: $\mathrm{N}=$ control group, $\mathrm{G}=$ group fed with Lactobacillus rhamnosus $\mathrm{GG}$, $\mathrm{K}=$ group fed with rifampicin-resistant Lactobacillus gasseri K7; 3 and 8 indicate 3 and 8 d postpartum, respectively.

in MG, both probiotics increased the abundance of Firmicutes. These differences persisted also at the family (Figure 3) and genus levels, where both probiotics increased the abundance of LAB genera (Table 2). It is reasonable to assume that the increased presence of $\mathrm{LAB}$ increased the rate of sampling of different $\mathrm{LAB}$ from the gut (Berg and Garlington, 1979). For example, probiotic strains Lactobacillus acidophilus LAFTI 110 and Lactobacillus paracasei LAFT1 126 increase the rate of translocation of anaerobic bacteria and Lactobacillus genus to MLN and cause greater phagocytic activity of the peritoneal macrophages in $\mathrm{BALB} / \mathrm{c}$ mice (Paturi et al., 2008). Strikingly, the reads assigned to the Lactobacillus genus appeared exclusively in MG or milk samples from probiotic groups. Jiménez et al.
(2008), in a study of 2 probiotics as an alternative for mastitis treatment, also reported that the Lactobacillus genus appeared exclusively in milk samples from probiotic groups.

The presence of reads assigned to Bifidobacterium, Bacteroides, Prevotella, Turicibacter, Barnesiella, Alistipes, and others in MLN and MG (Supplementary Table S3; http://dx.doi.org/10.3168/jds.2014-8519) suggests that some of these bacteria may originate from the intestine, because these are strictly anaerobic genera and typical representatives of fecal microbiota of humans and rodents. Representatives of fecal microbiota are frequently found in milk microbiota from humans and animals (Quigley et al., 2013), and obligate gut-associated anaerobes may be vertically transferred 
from mother to neonate via breastfeeding (Jost et al., 2014). In our study, Streptococcus were present in all MG samples, which is in concordance with human milk microbiota, where Streptococcus are frequently detected in milk samples (Hunt et al., 2011; Cabrera-Rubio et al., 2012; Jost et al., 2013; Ward et al., 2013). The overgrowth of Streptococcus in MG and milk from one of the animals belonging to the K8 group suggests a likely subclinical mastitis, because no clinical signs of mastitis were observed. Streptococci are potential agents of clinical and subclinical mastitis in cows, goats, and humans, and mastitis caused by streptococci is frequently studied in mice models (Notebaert and Meyer, 2006).

The calculated Chao1 richness estimate and nonparametric Shannon index for the species group (Figure 4) suggests that the administration of probiotics had a positive effect on MG and MLN microbiota. Lower estimated total number of species (Chao1) and increased distribution between species (Shannon index) compared with the control groups in MLN could mean a decreased risk of systemic infections due to the reduced likelihood of overgrowth of one the species in MLN. The increased estimated total number of species in both probiotic groups and increased distribution between species in the LGG group can be considered positive effects on MG microbiota. From the perspective of microbial populations in the MG, greater diversity can have a positive effect on the development of the immune system of the newborn but the distribution and presence of certain species can be crucial. Decreased distribution between species means a greater representation of certain species, which may increase the chance of infection of the MG (Delgado et al., 2008). In addition, treatment with LGG increased the abundance of Lactobacillus on d 3PP (Table 2) and the abundance of Bifidobacterium on d 8 PP (Supplementary Table S3; http://dx.doi.org/10.3168/jds.2014-8519). The presence of Lactobacillus and Bifidobacterium in mother's milk is believed to have a positive effect on the infant's health (Martín et al., 2003, 2009). It is important to emphasize that the abundance of sequences that belonged to probable contaminants was approximately the same between individual samples. Consequently, we argue that differences in richness between groups were due to differences in reads that were not contaminants. Furthermore, Chao1 is a nonparametric estimator, which is based on the assumption that rare species in the sample contain information about the unseen species (Chao et al., 2005). In our case, the rare species, with a small number of assigned reads, were assigned to representatives of anaerobic and facultative aerobic gram-positive bacteria that were most likely not the result of contamination.

\section{CONCLUSIONS}

Overall, the results of our study indicate that a link between probiotic application and MG microbiota exists. The effects of administration of probiotics LGG and LK7 to pregnant and lactating mice were reflected in an increased number of copies of $16 \mathrm{~S}$ rDNA, especially from Firmicutes and LAB genera, and by differences in Chao1 richness estimate and nonparametric Shannon index. The exact mechanism by which probiotics induce changes in MG microbiota remains elusive and most probably includes immunological aspects that were not assessed in this study. However, we speculate that the ability to influence the bacterial composition of MG and milk could represent a beneficial effect on the health of the MG and ultimately the health of the newborn. Because different strains differentially influence the MG microbiota, future research should focus on the identification and characterizations of those probiotic strains that are most efficient in modulating MG and milk microbiota to enhance their effects on the health of MG and the newborn.

\section{ACKNOWLEDGMENTS}

This research was supported by the Slovenian Research Agency (Ljubljana, Slovenia): Young researcher program (Contract No. 1000-09-310201, Primož Treven), the project J4-3606 and the program P4-0097.

\section{REFERENCES}

Abe, F., M. Muto, T. Yaeshima, K. Iwatsuki, H. Aihara, Y. Ohashi, and T. Fujisawa. 2010. Safety evaluation of probiotic bifidobacteria by analysis of mucin degradation activity and translocation ability. Anaerobe 16:131-136.

Abrahamsson, T. R., G. Sinkiewicz, T. Jakobsson, M. Fredrikson, and B. Bjorksten. 2009. Probiotic lactobacilli in breast milk and infant stool in relation to oral intake during the first year of life. J. Pediatr. Gastroenterol. Nutr. 49:349-354.

Ahlroos, T., and S. Tynkkynen. 2009. Quantitative strain-specific detection of Lactobacillus rhamnosus GG in human faecal samples by real-time PCR. J. Appl. Microbiol. 106:506-514.

Andersson, A. F., M. Lindberg, H. Jakobsson, F. Backhed, P. Nyren, and L. Engstrand. 2008. Comparative analysis of human gut microbiota by barcoded pyrosequencing. PLoS ONE 3:e2836.

Arroyo, R., V. Martin, A. Maldonado, E. Jimenez, L. Fernandez, and J. M. Rodriguez. 2010. Treatment of infectious mastitis during lactation: Antibiotics versus oral administration of lactobacilli isolated from breast milk. Clin. Infect. Dis. 50:1551-1558.

Asemi, Z., M. Samimi, Z. Tabassi, M. Naghibi Rad, A. Rahimi Foroushani, H. Khorammian, and A. Esmaillzadeh. 2013. Effect of daily consumption of probiotic yoghurt on insulin resistance in pregnant women: A randomized controlled trial. Eur. J. Clin. Nutr. 67:71-74.

Berg, R. D., and A. W. Garlington. 1979. Translocation of certain indigenous bacteria from the gastrointestinal tract to the mesenteric lymph nodes and other organs in a gnotobiotic mouse model. Infect. Immun. 23:403-411.

Biesbroek, G., E. A. M. Sanders, G. Roeselers, X. H. Wang, M. P. M. Caspers, K. Trzcinski, D. Bogaert, and B. J. F. Keijser. 2012. 
Deep sequencing analyses of low density microbial communities: Working at the boundary of accurate microbiota detection. PLoS ONE 7:e32942.

Blum, C. A., A. K. Wilson, and M. H. Bhattacharyya. 1999. A nest box to facilitate excreta collection from mouse dams through pregnancy, parturition, and lactation. Contemp. Top. Lab. Anim. Sci. 38:71-77.

Blümer, N., S. Sel, S. Virna, C. C. Patrascan, S. Zimmermann, U. Herz, H. Renz, and H. Garn. 2007. Perinatal maternal application of Lactobacillus rhamnosus GG suppresses allergic airway inflammation in mouse offspring. Clin. Exp. Allergy 37:348-357.

Bogovi Matijašić, B., M. Koman Rajšp, B. Perko, and I. Rogelj. 2007. Inhibition of Clostridium tyrobutyricum in cheese by Lactobacillus gasseri. Int. Dairy J. 17:157-166.

Brandt, K., and T. Alatossava. 2003. Specific identification of certain probiotic Lactobacillus rhamnosus strains with PCR primers based on phage-related sequences. Int. J. Food Microbiol. 84:189-196.

Cabrera-Rubio, R., M. C. Collado, K. Laitinen, S. Salminen, E. Isolauri, and A. Mira. 2012. The human milk microbiome changes over lactation and is shaped by maternal weight and mode of delivery. Am. J. Clin. Nutr. 96:544-551.

Champlot, S., C. Berthelot, M. Pruvost, E. A. Bennett, T. Grange, and E. M. Geigl. 2010. An efficient multistrategy DNA decontamination procedure of PCR reagents for hypersensitive PCR applications. PLoS ONE 5:e13042.

Chao, A. 1984. Nonparametric-estimation of the number of classes in a population. Scand. J. Stat. 11:265-270.

Chao, A., R. L. Chazdon, R. K. Colwell, and T. J. Shen. 2005. A new statistical approach for assessing similarity of species composition with incidence and abundance data. Ecol. Lett. 8:148-159.

Chao, A., and T. J. Shen. 2003. Nonparametric estimation of Shannon's index of diversity when there are unseen species in sample. Environ. Ecol. Stat. 10:429-443.

Collado, M. C., K. Laitinen, S. Salminen, and E. Isolauri. 2012. Maternal weight and excessive weight gain during pregnancy modify the immunomodulatory potential of breast milk. Pediatr. Res. $72: 77-85$

Crispie, F., M. Alonso-Gomez, C. O'Loughlin, K. Klostermann, J. Flynn, S. Arkins, W. Meaney, R. P. Ross, and C. Hill. 2008. Intramammary infusion of a live culture for treatment of bovine mastitis: Effect of live lactococci on the mammary immune response. J. Dairy Res. 75:374-384.

Delgado, S., R. Arroyo, R. Martin, and J. M. Rodriguez. 2008. PCRDGGE assessment of the bacterial diversity of breast milk in women with lactational infectious mastitis. BMC Infect. Dis. 8:51.

Dommels, Y. E. M., R. A. Kemperman, Y. E. M. P. Zebregs, R. B Draaisma, A. Jol, D. A. W. Wolvers, E. E. Vaughan, and R. Albers. 2009. Survival of Lactobacillus reuteri DSM 17938 and Lactobacillus rhamnosus GG in the human gastrointestinal tract with daily consumption of a low-fat probiotic spread. Appl. Environ. Microbiol. 75:6198-6204.

Fernandez, L., S. Langa, V. Martin, A. Maldonado, E. Jimenez, R. Martin, and J. M. Rodriguez. 2013. The human milk microbiota: Origin and potential roles in health and disease. Pharmacol. Res. $69: 1-10$.

Fierer, N., J. A. Jackson, R. Vilgalys, and R. B. Jackson. 2005. Assessment of soil microbial community structure by use of taxonspecific quantitative PCR assays. Appl. Environ. Microbiol. 71:4117-4120.

Gorbach, S. L. 2000. Probiotics and gastrointestinal health. Am. J. Gastroenterol. 95:S2-S4

Grahn, N., M. Olofsson, K. Ellnebo-Svedlund, H. E. Monstein, and J. Jonasson. 2003. Identification of mixed bacterial DNA contamination in broad-range PCR amplification of 16S rDNA V1 and V3 variable regions by pyrosequencing of cloned amplicons. FEMS Microbiol. Lett. 219:87-91.

Grönlund, M. M., L. Grzeskowiak, E. Isolauri, and S. Salminen. 2011. Influence of mother's intestinal microbiota on gut colonization in the infant. Gut Microbes 2:227-233.

Grzeskowiak, L., M. M. Grönlund, C. Beckmann, S. Salminen, A. von Berg, and E. Isolauri. 2012. The impact of perinatal probiotic in- tervention on gut microbiota: Double-blind placebo-controlled trials in Finland and Germany. Anaerobe 18:7-13.

Gueimonde, M., S. Sakata, M. Kalliomaki, E. Isolauri, Y. Benno, and S. Salminen. 2006. Effect of maternal consumption of Lactobacillus GG on transfer and establishment of fecal bifidobacterial microbiota in neonates. J. Pediatr. Gastroenterol. Nutr. 42:166-170.

Heikkilä, M. P., and P. E. J. Saris. 2003. Inhibition of Staphylococcus aureus by the commensal bacteria of human milk. J. Appl. Microbiol. 95:471-478.

Hobson, P. N. 1969. Rumen bacteria. Pages 133-149 in Methods in Microbiology. Vol. 3B. J. N. Norris and D. W. Ribbons, ed. Academic Press, London, UK.

Hughes, M. S., L. A. Beck, and R. A. Skuce. 1994. Identification and elimination of DNA-sequences in Taq DNA-polymerase. J. Clin. Microbiol. 32:2007-2008.

Hunt, K. M., J. A. Foster, L. J. Forney, U. M. E. Schutte, D. L. Beck, Z. Abdo, L. K. Fox, J. E. Williams, M. K. McGuire, and M. A. McGuire. 2011. Characterization of the diversity and temporal stability of bacterial communities in human milk. PLoS ONE 6:e21313.

Huurre, A., K. Laitinen, S. Rautava, M. Korkeamaki, and E. Isolauri. 2008. Impact of maternal atopy and probiotic supplementation during pregnancy on infant sensitization: A double-blind placebocontrolled study. Clin. Exp. Allergy 38:1342-1348.

Jeurink, P. V., J. van Bergenhenegouwen, E. Jimenez, L. M. J. Knippels, L. Fernandez, J. Garssen, J. Knol, J. M. Rodriguez, and R. Martin. 2013. Human milk: A source of more life than we imagine. Benef. Microbes 4:17-30.

Jiménez, E., L. Fernandez, A. Maldonado, R. Martin, M. Olivares, J. Xaus, and J. M. Rodriguez. 2008. Oral administration of Lactobacillus strains isolated from breast milk as an alternative for the treatment of infectious mastitis during lactation. Appl. Environ. Microbiol. 74:4650-4655.

Jost, T., C. Lacroix, C. Braegger, and C. Chassard. 2013. Assessment of bacterial diversity in breast milk using culture-dependent and culture-independent approaches. Br. J. Nutr. 110:1253-1262.

Jost, T., C. Lacroix, C. P. Braegger, F. Rochat, and C. Chassard. 2014. Vertical mother-neonate transfer of maternal gut bacteria via breastfeeding. Environ. Microbiol. 16:2891-2904.

Kandasamy, M., A. Selvakumari Jayasurya, S. Moochhala, B. Huat Bay, Y. Kun Lee, and R. Mahendran. 2011. Lactobacillus rhamnosus GG secreting an antigen and Interleukin-2 translocates across the gastrointestinal tract and induces an antigen specific immune response. Microbiol. Immunol. 55:704-714.

Kopp, M. V., I. Hennemuth, A. Heinzmann, and R. Urbanek. 2008. Randomized, double-blind, placebo-controlled trial of probiotics for primary prevention: No clinical effects of Lactobacillus GG supplementation. Pediatrics 121:e850-e856.

Lazarevic, V., N. Gaia, S. Emonet, M. Girard, G. Renzi, L. Despres, H. Wozniak, J. Y. Marcos, J. B. Veyrieras, S. Chatellier, A. van Belkum, J. Pugin, and J. Schrenzel. 2014. Challenges in the culture-independent analysis of oral and respiratory samples from intubated patients. Front. Cell. Infect. Microbiol. 4:65. 10.3389/ fcimb.2014.00065.

Mackie, R. I., A. Sghir, and H. R. Gaskins. 1999. Developmental microbial ecology of the neonatal gastrointestinal tract. Am. J. Clin. Nutr. 69:1035S-1045S.

Maragkoudakis, P. A., M. Papadelli, M. Georgalaki, E. G. Panayotopoulou, B. Martinez-Gonzalez, A. F. Mentis, K. Petraki, D. N. Sgouras, and E. Tsakalidou. 2009. In vitro and in vivo safety evaluation of the bacteriocin producer Streptococcus macedonicus ACADC 198. Int. J. Food Microbiol. 133:141-147.

Martín, R., E. Jimenez, H. Heilig, L. Fernandez, M. L. Marin, E. G. Zoetendal, and J. M. Rodriguez. 2009. Isolation of bifidobacteria from breast milk and assessment of the bifidobacterial population by PCR-denaturing gradient gel electrophoresis and quantitative real-time PCR. Appl. Environ. Microbiol. 75:965-969.

Martín, R., S. Langa, C. Reviriego, E. Jimenez, M. L. Marin, M. Olivares, J. Boza, J. Jimenez, L. Fernandez, J. Xaus, and J. M. Rodriguez. 2004. The commensal microflora of human milk: New perspectives for food bacteriotherapy and probiotics. Trends Food Sci. Technol. 15:121-127. 
Martín, R., S. Langa, C. Reviriego, E. Jimenez, M. L. Marin, J. Xaus, L. Fernandez, and J. M. Rodriguez. 2003. Human milk is a source of lactic acid bacteria for the infant gut. J. Pediatr. 143:754-758.

Matijašić, B. B., T. Obermajer, L. Lipoglavsek, I. Grabnar, G. Avgustin, and I. Rogelj. 2014. Association of dietary type with fecal microbiota in vegetarians and omnivores in Slovenia. Eur. J. Nutr. 53:1051-1064.

Matijašić, B. B., T. Obermajer, M. Zorič Peternel, S. Trachatova, A. Spanova, and I. Rogelj. 2009. Detection of the Lactobacillus gasseri $\mathrm{K} 7$ probiotic strain in feces and in human milk with molecular methods. Med. Razgl. 48(S3):137-138.

Nasiraii, L. R., F. Tabatabaie, B. Alaeddini, R. Noorbakhsh, R. M. Heravi, and S. Afsharian. 2011. Investigation of lactobacilli from mother's breast milk who were placed on probiotic diet. Afr. J. Microbiol. Res. 5:1581-1585.

Notebaert, S., and E. Meyer. 2006. Mouse models to study the pathogenesis and control of bovine mastitis. A review. Vet. Q. 28:2-13.

Ortiz-Andrellucchi, A., A. Sanchez-Villegas, C. Rodriguez-Gallego, A. Lemes, T. Molero, A. Soria, L. Pena-Quintana, M. Santana, O. Ramirez, J. Garcia, F. Cabrera, J. Cobo, and L. Serra-Majem. 2008. Immunomodulatory effects of the intake of fermented milk with Lactobacillus casei DN114001 in lactating mothers and their children. Br. J. Nutr. 100:834-845.

Paturi, G., M. Phillips, and K. Kailasapathy. 2008. Effect of probiotic strains Lactobacillus acidophilus LAFTI 110 and Lactobacillus paracasei LAFT1 126 on systemic immune functions and bacterial translocation in mice. J. Food Prot. 71:796-801.

Perez, P. F., J. Dore, M. Leclerc, F. Levenez, J. Benyacoub, P. Serrant, I. Segura-Roggero, E. J. Schiffrin, and A. Donnet-Hughes. 2007. Bacterial imprinting of the neonatal immune system: Lessons from maternal cells? Pediatrics 119:e724-732.

Prescott, S. L., K. Wickens, and L. Westcott. 2008. Supplementation with Lactobacillus rhamnosus or Bifidobacterium lactis probiotics in pregnancy increases cord blood interferon-gamma and breast milk transforming growth factor-beta and immunoglobin A detection. Clin. Exp. Allergy 38:1606-1614.

Quigley, L., O. O'Sullivan, C. Stanton, T. P. Beresford, R. P. Ross, G. F. Fitzgerald, and P. D. Cotter. 2013. The complex microbiota of raw milk. FEMS Microbiol. Rev. 37:664-698.

Rogelj, I., and B. B. Matijašić. 2006. Lactobacillus gasseri LF221 and K7-From isolation to application. Biologia 61:761-769.

Sagaya, F. M., B. Hacin, G. Tompa, A. Ihan, Š. Špela, M. Černe, R. F. Hurrell, B. B. Matijašić, I. Rogelj, and G. Vergères. 2014 Lactobacillus gasseri $\mathrm{K} 7$ modulates the blood cell transcriptome of conventional mice infected with Escherichia coli O157:H7. J. Appl. Microbiol. 116:1282-1296.

Salminen, S. 1996. Functional dairy foods with Lactobacillus strain GG. Nutr. Rev. 54:S99-101.

Salter, S. J., M. Cox, E. Turek, S. Calus, W. Cookson, M. Moffatt, P. Turner, J. Parkhill, N. Loman, and A. Walker. 2014. Reagent and laboratory contamination can critically impact sequence-based microbiome analyses. BMC Biol. 12:87.
Schloss, P. D., S. L. Westcott, T. Ryabin, J. R. Hall, M. Hartmann, E. B. Hollister, R. A. Lesniewski, B. B. Oakley, D. H. Parks, C. J. Robinson, J. W. Sahl, B. Stres, G. G. Thallinger, D. J. Van Horn, and C. F. Weber. 2009. Introducing mothur: Open-source, platform-independent, community-supported software for describing and comparing microbial communities. Appl. Environ. Microbiol. 75:7537-7541.

Schultz, M., C. Gottl, T. J. Young, T. Iwen, and T. A. Vanderhoof. 2004. Administration of oral probiotic bacteria to pregnant women causes temporary infantile colonization. J. Pediatr. Gastroenterol. Nutr. 38:293-297.

Soto, A., V. Martin, E. Jimenez, I. Mader, J. M. Rodriguez, and L. Fernandez. 2014. Lactobacilli and bifidobacteria in human breast milk: Influence of antibiotherapy and other host and clinical factors. J. Pediatr. Gastroenterol. Nutr. 59:78-88.

Spangler, R., N. L. Goddard, and D. S. Thaler. 2009. Optimizing Taq polymerase concentration for improved signal-to-noise in the broad range detection of low abundance bacteria. PLoS ONE 4:e7010.

Tanner, M. A., B. M. Goebel, M. A. Dojka, and N. R. Pace. 1998 Specific ribosomal DNA sequences from diverse environmental settings correlate with experimental contaminants. Appl. Environ. Microbiol. 64:3110-3113.

Teletchea, F., C. Maudet, and C. Hanni. 2005. Food and forensic molecular identification: Update and challenges. Trends Biotechnol. 23:359-366.

Treven, P., K. Turkova, A. Trmcic, T. Obermajer, I. Rogelj, and B. B. Matijasic. 2013. Detection and quantification of probiotic strain Lactobacillus gasseri $\mathrm{K} 7$ in faecal samples by targeting bacteriocin genes. Folia Microbiol. (Praha) 58:623-630.

Ward, T. L., S. Hosid, I. Ioshikhes, and I. Altosaar. 2013. Human milk metagenome: A functional capacity analysis. BMC Microbiol. 13:116.

Wells, C. L., M. A. Maddaus, and R. L. Simmons. 1988. Proposed mechanisms for the translocation of intestinal bacteria. Rev. Infect. Dis. 10:958-979.

West, P. A., J. H. Hewitt, and O. M. Murphy. 1979. Influence of methods of collection and storage on the bacteriology of human-milk. J. Appl. Bacteriol. 46:269-277.

Willner, D., J. Daly, D. Whiley, K. Grimwood, C. E. Wainwright, and P. Hugenholtz. 2012. Comparison of DNA extraction methods for microbial community profiling with an application to pediatric bronchoalveolar lavage samples. PLoS ONE 7:e34605.

Zhou, J. S., Q. Shu, K. J. Rutherfurd, J. Prasad, P. K. Gopal, and H. S. Gill. 2000. Acute oral toxicity and bacterial translocation studies on potentially probiotic strains of lactic acid bacteria. Food Chem. Toxicol. 38:153-161.

Zorič Peternel, M., A. Čanžek Majhenič, H. Holo, I. Nes, Z. Salehian, A. Berlec, and I. Rogelj. 2010. Wide-inhibitory spectra bacteriocins produced by Lactobacillus gasseri K7. Probiotics Antimicrob. Proteins 2:233-240. 